\title{
Adiponectin levels and its relation with insulin secretion and insulin sensitivity in a group of sub-Saharan African women with polycystic ovary syndrome
}

\author{
Audrey Synthia Momo ${ }^{*}$ (D, Vicky Jocélyne Ama Moor ${ }^{1,2}$, Aurel T. Tankeu³, Falmata Amazia', Guy Sadeu Wafeu4, \\ Magellan Guewo-Fokeng ${ }^{1}$, Esther Astrid Mbono Samba', Jan réné Nkeck ${ }^{1,5}$, Yannick Djieka ${ }^{5}$, \\ Christelle Chemaga Nkonpawa ${ }^{1}$, Floriane Djapa Tofeun ${ }^{1}$, Serge Guifo ${ }^{1}$, Julius Dohbit Sama ${ }^{7}$ and \\ Siméon Pierre Choukem ${ }^{6,8,9}$
}

\begin{abstract}
Objectives: Low levels of adiponectin have been reported in Polycystic Ovary Syndrome (PCOS). In sub-Saharan Africa, little data are available on the topic. We aimed to investigate the levels of adiponectin and its relation with insulin secretion and insulin sensitivity in women with PCOS in Yaoundé, Cameroon. A comparative cross-sectional study was conducted in 32 women presenting PCOS and 32 controls matched for age and Body Mass Index. For each participant, adiponectin levels were measured. We estimated insulin sensitivity using Homeostasis model index (HOMA-IR) and insulin secretion with C-peptide levels.

Results: Women with PCOS had higher insulin secretion levels than controls (C-peptide: $4.98 \pm 3.83$ vs $3.25 \pm 1.62$ $\mathrm{mUI} / \mathrm{l} ; p=0.02)$. Also, the HOMA-IR index was higher compared to that of women without PCOS $(1.15 \pm 0.90 \mathrm{vs}$ $0.77 \pm 0.38 ; p=0.03$ ) suggesting greater insulin resistance. The median [25th-75th percentile] values of adiponectin concentrations were similar between the two groups $(22.68[21.72-23.41] \mu \mathrm{g} / \mathrm{ml}$ vs 22.03 [21.40-22.93] $\mathrm{\mu g} / \mathrm{ml}$; $p=0.1$. There was no association between insulin sensitivity and adiponectin levels in the PCOS group. PCOS is not associated with changes in adiponectin in a population of sub-Saharan African women. Further studies are needed to shed more light on this condition.
\end{abstract}

Keywords: Adiponectin, Polycystic ovary syndrome, Insulin sensitivity

\section{Introduction}

Polycystic ovary syndrome (PCOS) is a complex and heterogenous condition characterized by hyperandrogenism, ovulatory dysfunction and polycystic ovarian morphology (PCOM) [1, 2]. It affects women of reproductive age

*Correspondence: audreysmomo95@gmail.com

${ }^{1}$ Department of Biochemistry and Physiological Sciences, Faculty

of Medicine and Biomedical Sciences, University of Yaoundé I, Yaoundé,

Cameroon

Full list of author information is available at the end of the article worldwide with an estimated prevalence of 5-20\% [1]. Metabolic abnormalities, mainly insulin resistance (IR) and compensatory hyperinsulinemia, are evident in a majority of affected individuals, especially among those women who also show hyperandrogenism [1]. It has been shown that $50-70 \%$ of women with PCOS are insulin resistant [3], half of them are overweight or obese with 5-7-folds increased risk of Type 2 diabetes (T2D) [4]. The mechanisms of IR in this condition remain poorly elucidated. Initially, IR was considered a consequence of 
obesity and overweight usually found in PCOS. However, recent evidence suggests that insulin resistance in PCOS might be independent of obesity [5]. In search of mechanisms and associated factors of IR, adipokines were proposed as a potential actor in the development of IR in PCOS [6]. Adiponectin is one of the most abundant adipokine, plays an important role in energy metabolism and contributes to the pathogenesis of the metabolic syndrome [6, 7]. It also exhibits anti-inflammatory, antiatherogenic and insulin-sensitizing effects [8]. Reduced levels of adiponectin have been associated with insulin resistance indicating a potential role in the development of metabolic disorders [9]. Given that, it has been suggested that adiponectin levels might be altered in PCOS participating to IR in this condition. However, this relationship between adiponectin levels and IR in PCOS remains debatable. Studies reports opposing results with some studies finding lower adiponectin levels in PCOS independent of BMI [10-12], and others reporting similar adiponectin levels in BMI-matched PCOS and controls $[13,14]$. But while these data are accumulating in different populations, data on this issue are lacking on sub-Saharan African populations. Therefore, studies are needed to provide data on this topic on a population where metabolic disorders are highly prevalent [15]. In this light, we aimed to study the levels of adiponectin in cameroonian women living with PCOS.

\section{Main text \\ Materials and methods Design/participants}

This comparative cross-sectional study was conducted from March to June 2020 at the Yaoundé GynaecoObstetric and Paediatric Hospital and at the laboratory of the Yaoundé Central Hospital. We included women of reproductive age (15-44 years) living with PCOS and controls matched for age and BMI (ratio 1:1). PCOS was defined according to the 2003 Rotterdam diagnosis criteria of PCOS; we therefore included in the PCOS group, women with at least 2 of the following criteria: (1) oligoor anovulation; (2) clinical and/or biological hyperandrogenism; (3) polycystic morphology of ovary in ultrasound examination (at least 12 follicles with a diameter of 2 to $9 \mathrm{~mm}$ and/or volume $\geq 10 \mathrm{ml}$ per ovary) [16]. Control subjects were healthy women recruited in the community, with no menstrual cycle disorders and no signs of clinical hyperandrogenism. We did not include women with any of the following conditions: pregnancy or breastfeeding, known diabetes mellitus, known chronic diseases or other hyperandrogenemia conditions (lateonset congenital adrenal hyperplasia, Cushing syndrome, androgen secreting tumors, and thyroid dysfunction). In addition, oral contraceptives or drugs that could affect hormonal and metabolic profiles were discontinued at least 3 months before inclusion in the study.

\section{Data collection}

For each subject, we measured weight with an automatic scale (CAMRY ${ }^{\circledR}$, Hong Kong, China) and Height with a stadiometer. Waist circumference (WC) and hip circumference $(\mathrm{HC})$ were measured using a measuring tape. We calculated Waist-to-hip ratio (WHR) as $\frac{\mathrm{WC}}{\mathrm{HC}}$ and body mass index (BMI) using the Quetelet's formula as $\mathrm{BMI}=$ weight $/$ height $^{2}\left(\mathrm{~kg} / \mathrm{m}^{2}\right)$. We grouped participants into 3 categories according to BMI: normal BMI (18.5$\left.24.9 \mathrm{~kg} / \mathrm{m}^{2}\right)$, overweight $\left(25.0-29.9 \mathrm{~kg} / \mathrm{m}^{2}\right)$ or obese $\left(\geq 30 \mathrm{~kg} / \mathrm{m}^{2}\right)$ [17]. We measured resting blood pressure using standardized procedures with a validated automated blood pressure measuring device, Omron HEM757(Omron Corporation, Tokyo, Japan).

\section{Blood samples and laboratory investigations}

After twelve hours of overnight fast, $10 \mathrm{ml}$ of venous blood were collected in the morning on the antecubital vein in dry tube and sodium fluoride tube. Fasting plasma glucose levels were determined the same day by an enzymatic colorimetric method using BIOLABO ${ }^{\circledR}$ kits (France). Serum was then aliquoted and stored at $-20{ }^{\circ} \mathrm{C}$ for further biochemical analysis (C-peptide and adiponectin). C-peptide and adiponectin were measured by an indirect sandwich Enzyme Linked Immuno-Sorbent Assay (ELISA) method (ELABSCIENCE ${ }^{\circledR}$ kits, USA).

\section{Determination of insulin resistance}

We used the Homeostasis Model Assessment of Insulin Resistance (HOMA-IR). This was determined by the formula: Fasting blood glucose $(\mathrm{mmol} / \mathrm{l}) \times$ Fasting insulin $(\mu \mathrm{UI} / \mathrm{ml}) / 22.5)$ where insulin was replaced by the C-peptide level as previously published in our context $[18,19]$.

\section{Statistical analysis}

Data were analyzed using SPSS version 23.0 software (IBM Corporation, Chicago, Illinois, USA). For quantitative variables, results are presented as mean \pm Standard Deviation (SD) for normally distributed data or median (25th-75th percentiles) when normality was not verified. For categorical variables, results are presented as counts (percentages). We used the Chi-square test to study association between categorical variables. The Student's T-test and non-parametric test (Mann-Whitney $U$-test) were used for group's comparison of quantitative variables. Spearman's correlation test was used to assess the linear association between skewed quantitative 
Table 1 Clinical characteristics of participants

\begin{tabular}{lccc}
\hline Variables & $\begin{array}{l}\text { PCOS } \\
\mathbf{n = 3 2}\end{array}$ & $\begin{array}{l}\text { Controls } \\
\mathbf{n = 3 2}\end{array}$ \\
\hline Age (years) & $26.7 \pm 4.7(20-38)$ & $27.1 \pm 4.9(18-38)$ & $p$ \\
Body mass index $(\mathrm{Kg} / \mathrm{m} 2)$ & $28.9 \pm 1.4(15.6-51.4)$ & $28.3 \pm 1.2(19.5-46.9)$ & 0.73 \\
Normal BMI & $10(31.3)$ & $10(31.3)$ & 0.72 \\
Overweight & $10(31.3)$ & $10(31.3)$ & 1 \\
Obese & $12(37.4)$ & $87.02 \pm 2.9(66-131)$ & 1 \\
Waist circumference $(\mathrm{cm})$ & $92.3 \pm 3.5(64-126)$ & $0.82 \pm 0.01(0.65-0.97)$ & 0.25 \\
Waist-to-hip ratio & $0.93 \pm 0.02(0.70-1.18)$ & $117.7 \pm 2.03(90-139)$ & 0.001 \\
Systolic blood pressure $(\mathrm{mm} \mathrm{Hg})$ & $118.3 \pm 2.08(102-160)$ & $79.1 \pm 1.5(58-107)$ & 0.41 \\
Diastolic blood pressure $(\mathrm{mm} \mathrm{Hg})$ & $77.2 \pm 1.8(60-120)$ & &
\end{tabular}

Values are count (percentages), mean \pm SD (range)

Test in bold represent significant values

Table 2 Biochemical characteristics of participants

\begin{tabular}{llll}
\hline Variables & $\begin{array}{l}\text { PCOS } \\
\mathbf{n}=\mathbf{3 2}\end{array}$ & $\begin{array}{l}\text { Controls } \\
\mathbf{n = 3 2}\end{array}$ & $\boldsymbol{p}$ \\
\hline Adiponectin $(\mu \mathrm{g} / \mathrm{ml})$ & $22.68[21.72-23.41]$ & $22.03[21.40-22.93]$ & 0.1 \\
Fasting plasma glucose $(\mathrm{mmol} / \mathrm{l})$ & $5.27 \pm 1.05$ & $5.35 \pm 0.94$ & 0.75 \\
C-peptide $(\mathrm{mUl} / \mathrm{l})$ & $4.98 \pm 3.83$ & $3.25 \pm 1.62$ & $\mathbf{0 . 0 2}$ \\
HOMA-IR index & $1.15 \pm 0.90$ & $0.77 \pm 0.38$ & $\mathbf{0 . 0 3}$
\end{tabular}

Values are median [25th-75th percentile] or mean \pm SD

Test in bold represent significant value

Table 3 Correlation between adiponectin levels and HOMA-IR index, C-peptide, fasting plasma glucose, Body mass index

\begin{tabular}{llllll}
\hline Variables & \multicolumn{4}{l}{ Adiponectin levels $(\boldsymbol{\mu g} / \mathbf{m l})$} \\
\cline { 2 - 3 } & \multicolumn{2}{l}{ PCOS } & & \multicolumn{2}{l}{ Controls } \\
\cline { 2 - 3 } \cline { 5 - 6 } & $\mathbf{r}$ & $\boldsymbol{p}$ & & $\mathbf{r}$ & $\boldsymbol{p}$ \\
\hline HOMA-IR index & -0.19 & 0.23 & & 0.03 & 0.89 \\
C-peptide (mUI/l) & -0.15 & 0.40 & & -0.04 & 0.82 \\
$\begin{array}{l}\text { Fasting plasma glucose } \\
\text { (mmol/l) }\end{array}$ & -0.23 & 0.20 & & 0.13 & 0.48 \\
BMI & 0.11 & 0.82 & & 0.32 & 0.08 \\
\hline
\end{tabular}

data and logistic regression to assess independent variables associated with PCOS. The receiver operating characteristic (ROC) curve analysis was used to evaluate the performance of adiponectin and Waist-to-hip ratio (WTH) in predicting PCOS. The significance threshold was set at $\mathrm{p}<0.05$.

\section{Results}

\section{Characteristics of the study population}

Overall, we enrolled 32 women with PCOS with a mean age of $26.7 \pm 4.7(20-38)$ years. Of these women, $31.3 \%$ had normal BMI, $31.3 \%$ were overweight and $37.4 \%$ were obese. The general characteristics of participants are summarized in (Table 1).

\section{Insulin resistance and adiponectin levels}

Women with PCOS had higher C-peptide levels compared to the controls $(4.98 \pm 3.83$ vs. $3.25 \pm 1.62 \mathrm{mUI} / \mathrm{l}$; $p=0.02)$, whereas their fasting plasma glucose levels were similar ( $5.27 \pm 1.05$ vs. $5.35 \pm 0.94 \mathrm{mmol} / \mathrm{l} ; p=0.75)$. As a result, their HOMA-IR index was higher compared to that of women without PCOS $(1.15 \pm 0.90 v s$. $0.76 \pm 0.38 ; p=0.03)$. Serum levels of adiponectin were similar between the two groups (Table 2).

In women with PCOS, we didn't find any correlation between adiponectin levels and the HOMA-IR index $(p=0.23)$ on one hand, nor between adiponectin levels and C-peptide, fasting plasma glucose, or BMI on the other hand (Table 3). After logistic regression analysis, we found that Waist-to-hip ratio was independent factor associated with PCOS (Additional file 1: Table S1). Waist-to-hip ratio presented with the best power in 
predicting $\mathrm{PCOS}(\mathrm{AUC}=0.76)$ followed by adiponectin $($ AUC $=0.62)$ (Additional file 1: Fig. S1).

\section{Discussion}

PCOS is frequently associated with IR leading to compensatory hyperinsulinemia [1]. In the present study, women with PCOS had a high HOMA-IR index compared to matched controls suggesting greater insulin resistance. These results are consistent with those of Amer et al. in Egypt where cases were more insulin resistant than controls using the same index [10]. In addition, Doh et al. in their report in fourteen Cameroonian women with PCOS, also found a low level of insulin sensitivity using the euglycemic hyperinsulinemic clamp, the reference method for estimating insulin sensitivity [20]. The C-peptide levels obtained, reflecting insulin secretion, were significantly higher in the PCOS group than controls suggesting hyperinsulinemia in this population as expected. In women with PCOS, basal insulin secretion rates are increased, although insulin secretory responses to a glucose load are generally inadequate resulting in a lower glucose disposition index than age and BMI-matched controls [21]. Despite the presence of hyperinsulinemia, women with PCOS are thought to have pancreatic $\beta$ cell dysfunction and also demonstrate decreased hepatic clearance of insulin [22]. Insulin potentiates steroidogenic response to gonadotrophins both in vivo and in vitro; hence, during hyperinsulinemia there will be elevated androgen levels. This increase androgen activity is associated with IR [23]. It has been hypothesized that PCOS results from a vicious circle of androgen excess favoring abdominal adipose tissue deposition and visceral adiposity by inducing IR and compensatory hyperinsulinism, which further facilitates androgen secretion by the ovaries and adrenal glands in women with PCOS [24].

Adiponectin values obtained in PCOS women fall within the known normal range of $5-30 \mu \mathrm{g} / \mathrm{mL}$ and were similar to the controls group [9]. Some studies report similar results in BMI-matched PCOS and controls $[13,14]$ whiles other report low levels of adiponectin independent of BMI [10-12]. As in our study, the authors did not find a relation between adiponectin levels and insulin resistance [11]. They attributed this changes to fat distribution and variable amount of subcutaneous and high visceral fat $[11,25]$. In our study, we found that WTH was independent factor associated with PCOS and have the best discriminatory power in predicting PCOS with an AUC of 0.76. One study showed that it can be used as indirect predictors of visceral obesity in women with PCOS [26]. Therefore, this abdominal obesity could cause additional disturbances in metabolic and hormonal parameters in PCOS [27]. The comparable results between PCOS and controls in our study suggest a relatively increase level of adiponectin in our population. Considering that this is the first study in this population, we speculate that this relative increase in adiponectin may reflect a resistance to its action [28]. This can either be a low sensitivity to this hormone, or a post-receptor resistance leading to a compensatory mechanism increasing hormonal levels.

We did not found a relation between adiponectin levels and insulin sensitivity in women with PCOS. Similar results were reported in Poland population [29]. However, studies in the Caucasian population report an association between adiponectin and insulin sensitivity $[12,30]$. These discrepancies between our findings and reports in other populations further stress the need of studies on the question in sub-Saharan populations.

\section{Conclusion}

Sub-Saharan African women with PCOS do not present lower adiponectin levels despite higher insulin resistance and high insulin secretion levels. Further studies are needed to shed more light on this condition.

\section{Limitations}

Firstly, we used C-peptide measurement to access insulin level base on their equimolar secretion in blood. Therefore, it can be indirectly measured to access insulin secretion [31]. Secondly, HOMA-IR index was used to determine insulin sensitivity instead of the gold standard method (the euglycaemic hyperinsulinic clamp) used in a small number of subjects [32]. Although, studies recommend the use of HOMA-IR index when it is impossible or difficult to perform [33]. In addition, the HOMA-IR index is more suitable for population and epidemiological studies [18].

\section{Abbreviations}

BMI: Body mass index; HC: Hip circumference; HOMA-IR: Homeostasis Model Assessment of Insulin Resistance; PCOS: Polycystic ovary syndrome; IR: Insulin resistance; SD: Standard deviation; T2D: Type 2 diabetes; WC: Waist circumference; WHR: Waist to Hip Ratio; AUC: Area under the curve; ROC: Receiver operating characteristic.

\section{Supplementary Information}

The online version contains supplementary material available at https://doi. org/10.1186/s13104-021-05878-0.

Additional file 1: Table S1. Logistic regression including key independent variables and factors associated with PCOS. Figure S1. Receiver operating characteristic (ROC) curve was based on binary logistic regression and classification analysis for PCOS and control group. AUC: Area under the curve. 


\section{Acknowledgements}

We gratefully acknowledge all the patients who have accepted to take part in this study.

\section{Authors' contributions}

ASM, ATT and SPC designed the study; ASM, JVAM, YD, JN, EAMS, FA, MGF, CCN, FDT, SG, JDS and SPC collected the data; ASM, ATT, GSW performed the statistical analysis; ASM, JVAM, ATT and SPC drafted the manuscript; All authors have read and approved the final manuscript.

\section{Funding}

None.

\section{Availability of data and materials}

Data will be available from the corresponding author upon request.

\section{Declarations}

\section{Ethical approval and consent to participate}

The study protocol was approved by the Institutional Research Ethical Committee of the Faculty of Medicine and Biomedical Sciences, Yaoundé and by the Centre Regional Ethics Committee for Human Health Research ( ${ }^{\circ}$ 0620/ CRERSHC/2020). All participants signed a written informed consent form.

\section{Consent for publication}

Not applicable.

\section{Competing interests}

None declared.

\section{Author details}

${ }^{1}$ Department of Biochemistry and Physiological Sciences, Faculty of Medicine and Biomedical Sciences, University of Yaoundé I, Yaoundé, Cameroon. ${ }^{2}$ Laboratory of Biochemistry, University Teaching Hospital, Yaoundé, Cameroon. ${ }^{3}$ Department of Biomedical Sciences, Faculty of Biology and Medicine, University of Lausanne, Lausanne, Switzerland. ${ }^{4}$ Center for Research on Filariasis and Other Tropical Diseases, Yaoundé, Cameroon. ${ }^{5}$ Department of Internal Medicine and Specialties, Faculty of Medicine and Biomedical Sciences, University of Yaoundé I, Yaoundé, Cameroon. ${ }^{6} \mathrm{Health}$ and Human Development Research Network, Douala, Cameroon. ${ }^{7}$ Department of Obstetrics and Gynecology, Faculty of Medicine and Biomedical Sciences, University of Yaoundé 1, Yaoundé, Cameroon. ${ }^{8}$ Department of Internal Medicine and Specialties, Faculty of Medicine and Pharmaceutical Sciences, University of Dschang Dschang, Cameroon. ${ }^{9}$ Department of Internal Medicine, Douala General Hospital, Douala, Cameroon.
\end{abstract}

Received: 14 June 2021 Accepted: 6 December 2021

Published online: 28 January 2022

\section{References}

1. Azziz R, Carmina E, Chen Z, Dunaif A, Laven JSE, Legro RS, et al. Polycystic ovary syndrome. Nat Rev Dis Primers. 2016;2(1):16057.

2. Teede H, Deeks A, Moran L. Polycystic ovary syndrome: a complex condition with psychological, reproductive and metabolic manifestations that impacts on health across the lifespan. BMC Med. 2010:8(1):41.

3. Azziz R, Carmina E, Dewailly D, Diamanti-Kandarakis E, Escobar-Morreale HF, Futterweit W, et al. The Androgen Excess and PCOS Society criteria for the polycystic ovary syndrome: the complete task force report. Fertil Steril. 2009;91(2):456-88.

4. Azziz R, Adashi EY. Stein and Leventhal: 80 years on. Am J Obstet Gynecol. 2016;214(2):247.e1-247.e11.

5. Stepto NK, Cassar S, Joham AE, Hutchison SK, Harrison CL, Goldstein RF, et al. Women with polycystic ovary syndrome have intrinsic insulin resistance on euglycaemic-hyperinsulaemic clamp. Hum Reprod. 2013;28(3):777-84.

6. Eckel J. Adipose tissue. In: Eckel J, editor. The cellular secretome and organ crosstalk. Cambridge: Academic press; 2018. p. 9-63.
7. Polak K, Czyzyk A, Simoncini T, Meczekalski B. New markers of insulin resistance in polycystic ovary syndrome. J Endocrinol Invest. 2017:40(1):1-8.

8. Stern JH, Rutkowski JM, Scherer PE. Adiponectin, leptin, and fatty acids in the maintenance of metabolic homeostasis through adipose tissue crosstalk. Cell Metab. 2016;23(5):770-84.

9. Ziemke F, Mantzoros CS. Adiponectin in insulin resistance: lessons from translational research. Am J Clin Nutr. 2010;91(1):258S-261S.

10. Amer H, Abo-Shady R, Elaziz D, Khattab Y. The role of serum adiponectin levels in women with polycystic ovarian syndrome. Egypt J Hosp Med. 2017;68:837-44.

11. Carmina E, Orio F, Palomba S, Cascella T, Longo RA, Colao AM, et al. Evidence for altered adipocyte function in polycystic ovary syndrome. Eur J Endocrinol. 2005;152(3):389-94.

12. Ardawi MSM, Rouzi AA. Plasma adiponectin and insulin resistance in women with polycystic ovary syndrome. Fertil Steril. 2005;83(6):1708-16.

13. Orio F, Palomba S, Cascella T, Milan G, Mioni R, Pagano C, et al. Adiponectin levels in women with polycystic ovary syndrome. J Clin Endocrinol Metab. 2003;88(6):2619-23

14. Lecke SB, Mattei F, Morsch DM, Spritzer PM. Abdominal subcutaneous fat gene expression and circulating levels of leptin and adiponectin in polycystic ovary syndrome. Fertil Steril. 2011;95(6):2044-9.

15. Maya ET, Guure CB, Adanu RMK, Sarfo B, Ntumy M, Bonney EY, et al. Why we need epidemiologic studies of polycystic ovary syndrome in Africa. Int J Gynecol Obstet. 2018;143(2):251-4

16. Tr E, ASRM-Sponsored PCOS Consensus Workshop Group. Revised 2003 consensus on diagnostic criteria and long-term health risks related to polycystic ovary syndrome. Fertil Steril. 2004;81(1):19-25.

17. World Health Organization. Obesity: preventing and managing the global epidemic Report of a WHO consultation. World Health Organ Tech Rep Ser. 2000;894(i-xii):1-253.

18. Matthews DR, Hosker JP, Rudenski AS, Naylor BA, Treacher DF, Turner RC. Homeostasis model assessment: insulin resistance and ?-cell function from fasting plasma glucose and insulin concentrations in man. Diabetologia. 1985;28(7):412-9.

19. Noumegni SR, Bigna JJ, Ama Moor epse Nkegoum VJ, Nansseu JR, Assah FK, Jingi AM, et al. Relationship between estimated cardiovascular disease risk and insulin resistance in a black African population living with HIV: a cross-sectional study from Cameroon. BMJ Open. 2017;7(8): e016835.

20. Doh E, Mbanya A, Kemfang-Ngowa JD, Dohbit S, Tchana-Sinou M, Foumane $\mathrm{P}$, et al. The relationship between adiposity and insulin sensitivity in african women living with the polycystic ovarian syndrome: a clamp study. Int J Endocrinol. 2016;2016:1-6.

21. Ehrmann DA, et al. Insulin secretory defects in polycystic ovary syndrome. Relationship to insulin sensitivity and family history of non-insulindependent diabetes mellitus. J Clin Invest. 1995;96:520-7.

22. Dunaif A. Insulin resistance and the polycystic ovary syndrome: mechanism and implications for pathogenesis. Endocr Rev. 1997;18(6):774-800.

23. Poretsky L, Cataldo NA, Rosenwaks Z, Giudice LC. The insulinrelated ovarian regulatory system in health and disease. Endocr Rev. 1999;20(4):535-82.

24. Escobar-Morreale HF. Polycystic ovary syndrome: definition, aetiology, diagnosis and treatment. Nat Rev Endocrinol. 2018;14(5):270-84.

25. Aroda V, Ciaraldi TP, Chang S-A, Dahan MH, Chang RJ, Henry RR. Circulating and cellular adiponectin in polycystic ovary syndrome: relationship to glucose tolerance and insulin action. Fertil Steril. 2008;89(5):1200-8.

26. Kałużna M, Czlapka-Matyasik M, Bykowska-Derda A, Moczko J, Ruchala M, Ziemnicka K. Indirect predictors of visceral adipose tissue in women with polycystic ovary syndrome: a comparison of methods. Nutrients. 2021:13(8):2494.

27. Franik G, Bizoń A, Włoch S, Pluta D, Blukacz Ł, Milnerowicz H, et al. The effect of abdominal obesity in patients with polycystic ovary syndrome on metabolic parameters. Eur Rev Med Pharmacol Sci. 2017;21(21):4755-61.

28. Engin A. Adiponectin-resistance in obesity. In: Engin AB, Engin A, editors. Obesity and lipotoxicity. Cham: Springer International Publishing; 2017. p. 415-41.

29. Olszanecka-Glinianowicz M, Kuglin D, Dąbkowska-Huć A, Skałba P. Serum adiponectin and resistin in relation to insulin resistance and markers of hyperandrogenism in lean and obese women with polycystic ovary syndrome. Eur J Obstet Gynecol Reprod Biol. 2011;154(1):51-6. 
30. Liu X, Zhang J, Li Y, et al. On the relationship between serum total adiponectin and insulin resistance in polycystic ovary syndrome. Sheng Wu Yi Xue Gong Cheng Xue Za Zhi. 2010;27:636-40.

31. Palmer JP, Fleming GA, Greenbaum CJ, Herold KC, Jansa LD, Kolb H, et al. C-peptide is the appropriate outcome measure for type 1 diabetes clinical trials to preserve -cell function: report of an ADA workshop, 21-22 october 2001. Diabetes. 2004;53(1):250-64.

32. Wallace T, Matthews $D$. The assessment of insulin resistance in man. Diabet Med. 2002;19:527-34.

33. Bonora E, Targher G, Alberiche M, Bonadonna R, Saggiani F, Zenere M, et al. Homeostasis model assessment closely mirrors the glucose clamp technique in the assessment of insulin sensitivity: studies in subjects with various degrees of glucose tolerance and insulin sensitivity. Diabetes Care. 2000. https://doi.org/10.2337/diacare.23.1.57.

\section{Publisher's Note}

Springer Nature remains neutral with regard to jurisdictional claims in published maps and institutional affiliations.

- fast, convenient online submission

- thorough peer review by experienced researchers in your field

- rapid publication on acceptance

- support for research data, including large and complex data types

- gold Open Access which fosters wider collaboration and increased citations

- maximum visibility for your research: over 100M website views per year

At BMC, research is always in progress.

Learn more biomedcentral.com/submissions 